\title{
Plant community attributes affect dry grassland orchid establishment
}

\section{Antonio Slaviero, Silvia Del Vecchio, Simon Pierce, Edy Fantinato \& Gabriella Buffa}

\section{Plant Ecology}

An International Journal

ISSN 1385-0237

Volume 217

Number 12

Plant Ecol (2016) 217:1533-1543

DOI 10.1007/s11258-016-0666-x

\section{Plant Ecology}

VOLUME 217 NUMBER 12 DECEMBER 2016 ISSN 1385-0237 AN INTERNATIONAL JOURNAL

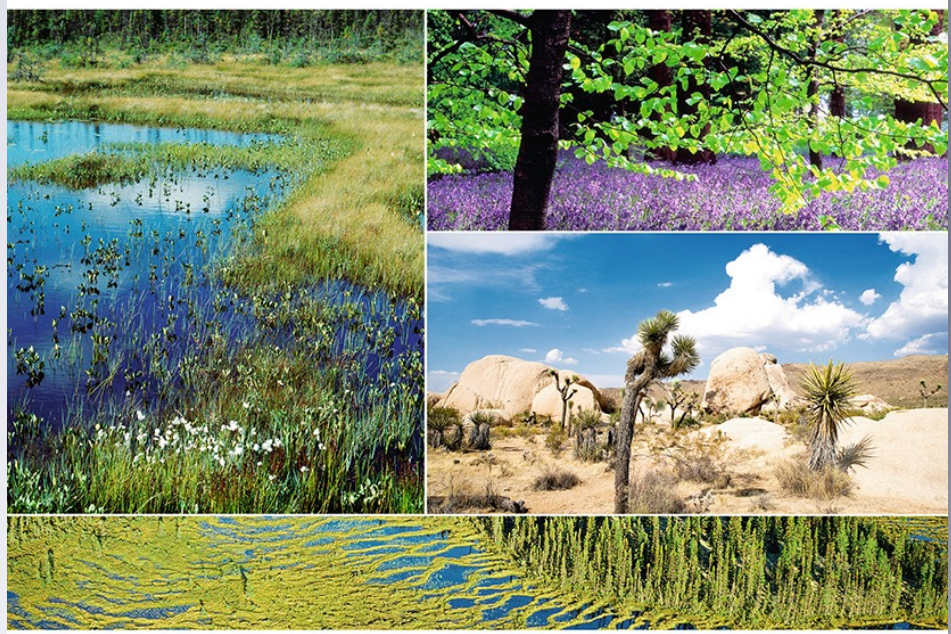

Springer 
Your article is protected by copyright and all rights are held exclusively by Springer Science +Business Media Dordrecht. This e-offprint is for personal use only and shall not be selfarchived in electronic repositories. If you wish to self-archive your article, please use the accepted manuscript version for posting on your own website. You may further deposit the accepted manuscript version in any repository, provided it is only made publicly available 12 months after official publication or later and provided acknowledgement is given to the original source of publication and a link is inserted to the published article on Springer's website. The link must be accompanied by the following text: "The final publication is available at link.springer.com". 


\title{
Plant community attributes affect dry grassland orchid establishment
}

\author{
Antonio Slaviero $\cdot$ Silvia Del Vecchio $\cdot$ Simon Pierce $\cdot$ Edy Fantinato $\cdot$ Gabriella Buffa
}

Received: 13 July 2016/Accepted: 24 September 2016/Published online: 29 September 2016

(C) Springer Science+Business Media Dordrecht 2016

\begin{abstract}
Several factors have been taken into account to explain the distribution of orchid species. We explored the extent to which plant community attributes affect the abundance and reproductive fitness of three orchid species (Anacamptis morio, Himantoglossum adriaticum and Ophrys sphegodes), native to dry grasslands. Structural attributes of plant community (e.g. cover and height) were assessed in ninety $4 \mathrm{~m}^{2}$ plots scattered on three hill massifs of the Veneto Region (NE Italy). For the three target orchid species, the height of the flowering stalk, the relative ramet height and the number of flowers and fruits were recorded in 203 tagged ramets. Generalized Linear Model revealed that plant community attributes such as cover and height of the herb layer exert a negative effect on the abundance of orchid populations. Furthermore, regression models indicated that $O$. sphegodes and $H$. adriaticum reproductive fitness,
\end{abstract}

Communicated by Timothy Bell.

\footnotetext{
A. Slaviero $\cdot$ S. Del Vecchio $\cdot$ E. Fantinato

G. Buffa $(\bowtie)$

Department of Environmental Sciences, Informatics and Statistics (DAIS), Ca' Foscari University of Venice, Via Torino 155, 30172 Venice, Italy

e-mail: gabriella.buffa@unive.it

S. Pierce

Department of Agricultural and Environmental Sciences (DiSAA), University of Milan, Via G. Celoria 2,

20133 Milan, Italy
}

determined as fruit/flower ratio, was positively affected by relative ramet height. Our results revealed that local herbaceous vegetation structure influences the cover and fruit set of target orchid species. However, there can be substantial variation in the response of different species and variation in the structural attributes of surrounding vegetation may be associated with differences in the strength of selection. In order to achieve effective results in orchid species conservation, protocols for the in situ conservation must detail the range of vegetation covers and heights at which orchid species are favoured and can produce the most effective inflorescences.

Keywords Himantoglossum adriaticum - Microsite limitation · Orchids · Plant community structure · Pollinator-mediated selection $\cdot$ Species interactions

\section{Introduction}

Biodiversity loss has become an impelling global concern. Species loss can be seen as a composite response to various human-induced changes such as habitat loss and degradation, unsustainable use of wild species, changes in traditional management methods, introduced species and global climate change (Sharrock and Jones 2009; Dengler et al. 2014). These processes have a particularly negative impact on plant species that occupy a narrow niche and/or have particular ecological requirements for germination, 
seedling establishment and reproduction (e.g. Fischer and Stöcklin 1997; Sonkoly et al. 2016; Thuiller et al. 2005).

Orchid species are characterised by a high degree of ecological specialisation (Pierce and Belotti 2011) and are threatened worldwide (Swarts and Dixon 2009). In terms of number of species, Orchidaceae are the most diverse of all flowering plant families (Swarts and Dixon 2009). Two-thirds of orchid species occur in the tropics as epiphytes, with terrestrial species comprising the remaining third, yet almost half of the extinct species are terrestrial herbaceous perennials (IUCN 1999). From an ecological perspective, orchids are fascinating because of their complex life cycle, involving a vast array of reproductive variability and pollination mechanisms (Cozzolino and Widmer 2005; Roy and Widmer 1999), and ubiquitous interactions with mycorrhizal fungi (Burgeff 1959). Orchids are also important from a biodiversity perspective for the large variety of life strategies evident among species (Swarts and Dixon 2009). Furthermore, orchid populations differ greatly in distribution and abundance, varying from plentiful to extremely rare even in apparently ideal habitat (Pierce et al. 2006). All these features highlight their intrinsic value as bioindicators and as research tools for defining patterns and processes that constrain how species assemble into local communities and for tuning conservation measures targeted at particularly rare species.

The conservation of orchid species is an ambitious target in the most industrialised European countries due to extensive loss of natural habitats and/or lack of suitable environmental conditions for these species to persist (Vogt-Schilb et al. 2015). Despite its richness worldwide, the Orchidaceae family is represented only by a small number of taxa in Europe (approximately 300 according to Delforge 2001), all with the temperate terrestrial life form. Most European species are reported to face alarming decline and species associated with woodlands and calcareous grasslands seem to suffer greater contractions in range than species associated with other habitats (Kull and Hutchings 2006; Pierce et al. 2006). Calcareous dry grassland orchids in particular are threatened due to the abandonment of traditional low-intensity agricultural regimes that have maintained their habitat for centuries, but have been neglected with the spread of industrialised agriculture since the mid 1900s (Willems et al. 1993).
Several of the best-known models of species coexistence explain the abundance and distribution of plant species within a community as a balance between environmental (abiotic) and biotic filters such as competitive and facilitative interactions among plant species (Brooker et al. 2008; Mason et al. 2011) or between plants and other organisms (Moeller 2004; Strauss and Irwin 2004). At the local scale, plant species distribution seems to be influenced by processes underlying mortality at early stages: germination and seedling establishment (Tsvuura et al. 2010; Jacquemyn and Brys 2015). Seeds may have very specific ecological requirements to overcome dormancy and initiate the growth of the embryo (Baskin and Baskin 2014), while seedlings need resources and a protected environment to resist environmental harshness, herbivory or parasitic attacks and become adult plants (Eriksson 1995; Moles and Westoby 2004). In particular, two processes are thought to limit plant recruitment: seed limitation and establishment limitation or microsite availability (Svenning et al. 2008; García-Camacho et al. 2010). Microsite limitation is determined by factors that constrain the recruitment of new individuals into the seedling population, regardless of the number of seeds that arrive at a site and is regulated by both abiotic (e.g. light, water, nutrients, soil structure) and biotic (e.g. competition and predation) factors that affect germination, seed and seedling survival. Thus, at the local scale, the availability of favourable sites for a permanent establishment of juvenile plants is essential for a species to overcome the selection and persist within the community (Clark et al. 1999). The concept of microsite limitation could apply not only to establishment and onward growth but to most processes in a plant life cycle, such as flowering and pollination, which is the initial step in seed formation. Namely, if fruit and seed production are improved, then the frequency of seedling establishment is likely to respond positively and result in an increase in population size (Ackerman et al. 1996).

Several of the above-mentioned factors have been taken into account to explain the distribution of orchid species, and particular attention has been given to climatic conditions (Wotavová et al. 2004), nutrient availability (Silvertown et al. 1994), physic environmental (Djordjević et al. 2016; Kull and Hutchings 2006; Tsiftsis et al. 2008) and anthropogenic disturbance such as fire and grazing (Coates et al. 2006; Gregg 2004; Hutchings et al. 1998; Janišová et al. 
2011). However, the extant vegetation may further modify microsite availability through such community attributes as the thickness of the litter layer or percentage cover of vegetation, and through indirect effects on the microclimate (e.g. light). In this case, not only the identity of the orchid species but the structure of the surrounding community would be most important in determining survival. The issue is of pivotal importance in semi-natural habitats such as dry grasslands. Temperate dry grasslands are mostly semi-natural communities maintained by traditional human management practices as mowing, pasturing and haymaking (Janišová et al. 2011; Habel et al. 2013; Dengler et al. 2014), which have been proven to regulate species composition and richness (Valkó et al. 2012). Much evidence has been found to indicate that abandonment of dry grasslands results in structural changes such as an increasing dominance of grasses and the development of thermophile fringe vegetation and scrubland facies (Biondi et al. 2006; Bobbik and Willems 1987), with possible impacts on weakly competitive species such as orchids. Thus, the interactions between orchid species and the extant community might be the key to understanding orchid recruitment output.

In light of this, the aim of this study was to explore the extent to which plant community attributes affect the establishment, abundance and reproductive fitness of orchid species in dry grasslands. In particular, we hypothesised that community structural characteristics such as herbaceous and woody species height and cover imposed constraints on three orchid species (Anacamptis morio L., Himantoglossum adriaticum H. Baumann and Ophrys sphegodes Mill.), native to dry grasslands and nearby ecotonal mesoxeric scrubland patches. Himantoglossum adriaticum is also recognised by Annex II of the EU Habitats Directive 92/43/EEC on the conservation of natural habitats and of wild fauna and flora (Anonymous 1992) as a species of Community interest for which habitat conservation is particularly important, and the present work also aimed to provide insight into the habitat characteristics impacting the in situ conservation of this species. Indeed, from the perspective of preserving biodiversity, investigating the limiting factors of each species' colonisation potential may allow predictions of range changes and the formulation of management strategies for rare plants.

\section{Methods}

Study area

The study took place on three hill massifs of the Veneto Region of NE Italy: the Eastern Lessini Mounts, Berici Hills and the Euganean Hills, which host a rich suite of endangered or endemic species and several rare orchids.

The study area encompasses several low-altitude hills with a major peak at $602 \mathrm{~m}$ a.s.l., originating from sedimentary (limestone and marl) and volcanic (basaltic and rhyolitic) bedrock. Study sites were represented by small- to medium-sized (0.2-2 ha) dry grasslands, dispersed in an agricultural landscape among forests and arable fields. The study was conducted on semi-natural, oligo- to mesotrophic, Bromus erectus-dominated dry grasslands (Natura 2000 code 6210 "Semi-natural dry grasslands and scrubland facies on calcareous substrates (FestucoBrometalia) (*important orchid sites)"). They develop on middle-altitude limestone slopes (50-450 m a.s.1.), on sites characterised by poorly developed, shallow and skeletal calcareous soils (Inceptisols and Entisols), with a very low soil available water content (AWC), and average $\mathrm{pH}$ of 7.5 (Bini 2001). When well conserved, the community structure is mainly determined by hemicryptophytes and, subordinately, chamaephytes. The vegetation is dominated by few, highly covering, anemophilous species (e.g. Bromus erectus, Artemisia alba, Catapodium rigidum, Koeleria pyramidata, Carex hallerana, Bothriochloa ischaemum) and numerous entomophilous species, such as Bupleurum gussonei, Scabiosa triandra, Fumana procumbens, Helianthemum nummularium ssp. obscurum, Convolvulus cantabrica and Globularia bisnagarica (Fantinato et al. 2016).

Once exploited for haymaking or cattle grazing, dry grasslands have experienced increasing abandonment. Since their inclusion in the Natura 2000 network as SCI/SPA, they are partly subjected to management such as mowing and grazing, with a frequency of once a year to once every 3 years.

Data collection

Vegetation was sampled during spring-summer (April-June) in 2014 using both a preferential (on 
target orchid populations) and a stratified random sampling design. To avoid spatial autocorrelation, the average distance between plots was set at more than $270 \mathrm{~m}$ (Rezende et al. 2015). In total, data from ninety $4 \mathrm{~m}^{2}$ plots were collected, resulting in 51 plots with the presence of target orchid species, and 39 without. In each plot, the plant community attributes were described by visually estimating total percentage cover, percentage cover and average height of all layers, and the cover of each vascular plant species. Orchid species cover was visually estimated as percent cover of rosettes. Furthermore, as synthetic descriptors of the community structure, we calculated the species richness (S), as the total number of vascular species, and Pielou's evenness index (J), which are among the most popular diversity indices in vegetation analysis (Gurevitch et al. 2002; Magurran 2004; Ricotta 2007).

Moreover, for the three target orchid species, 203 ramets (59 for A. morio, 52 for H. adriaticum and 92 for $O$. sphegodes) were tagged to record the height of the flowering stalk, and the number of flowers and fruits. The number of tagged ramets per plot represented at least $5 \%$ of the local density of flowering ramets (number of flowering stalks $/ 4 \mathrm{~m}^{2}$ plot) and, for very small populations (local density of flowering ramets $\leq 5 \%$ ), it coincided with the total number of flowering ramets. Data were collected at the peak of the flowering season following the protocols described in Cornelissen et al. (2003). The fruit/flower ratio of each ramet was used as an estimate of reproductive fitness.

Additionally, to describe the relationship between target species' ramets and the closest surrounding vegetation, we calculated the relative ramet height of each ramet as the difference between the flowering stalk height and the mean herbaceous vegetation height. The relative ramet height has a positive value when the flowering stalk is taller than the surrounding vegetation, and is otherwise negative, i.e. the surrounding vegetation overtops the entire above-ground shoot of the orchid.

\section{Data analysis}

To quantify the effect of plant community attributes on the abundance of orchid populations, a Generalized Linear Model (GLZ) was performed considering orchid cover as the covariate and species richness
(S), evenness index ( $\mathrm{J})$, total vegetation cover, and the percentage cover and average height of all layers as independent variables. The model was performed using R software ( $\mathrm{R}$ package MASS; Venables and Ripley 2002), using a Negative Binomial error distribution and a Log link function.

To assess the effect of community structure on orchid reproductive fitness, a Regression Model was built for each target species in Statistica 8.0 (StatSoft Inc. 2007) using the fruit/flower ratio as the covariate and the relative ramet height as the predictor.

\section{Results}

The surveyed plots exhibited a very rich cumulative species pool ( 249 species were counted overall), with a mean species richness $(\mathrm{S})$ per plot of $24( \pm 5.28 \mathrm{SD})$, ranging from a minimum of 12 to a maximum of 41 . According to the evenness index $(\mathrm{J})$, species were relatively equally distributed in the majority of surveyed plots, with an average value of $0.72( \pm 0.11$ $\mathrm{SD})$. The total percentage cover and the cover of the herb layer were generally high $(83.4 \pm 13.18$ and $72.3 \pm 13.63 \%$, respectively). Although normally lower, the shrub cover was much more variable, ranging from 0 to $65 \%$, with an average value of $6.82 \%( \pm 13.04 \mathrm{SD})$. The height of the herb layer ranged from 10 to $99 \mathrm{~cm}$ (mean $34.9 \mathrm{~cm} \pm 14.56 \mathrm{SD}$ ), and the shrub layer was also variable, with an average value of $167 \mathrm{~cm}( \pm 44.98 \mathrm{SD})$. Target orchid species cover was highly variable, ranging from 0 to $23 \%$, with an average value of $4.4 \%$.

GLZ model (Table 1) revealed that both the cover and height of the herb layer had a significant effect on the dependent variable, with a negative trend (Fig. 1), while neither the total cover nor the cover and height of the shrub layer, nor $\mathrm{S}$ and $\mathrm{J}$ exhibited significant effects.

Regression models on the fruit/flower ratio (Table 2; Fig. 2) revealed that the proportion of fertilised flowers in the wild was significantly affected by relative ramet height both for $O$. sphegodes $(\beta=0.435, \quad p \beta<0.001)$ and $H$. adriaticum $(\beta=0.88, p \beta<0.001)$. In particular, a very high closeness of fit was obtained for $H$. adriaticum (Adj $\left.R^{2}=0.771\right)$. However, such a relationship was not evident for A. morio $(F=0.0003, p F<0.987)$. 
Table 1 Results for negative binomial generalized linear model on target orchid cover

\begin{tabular}{|c|c|c|c|c|c|}
\hline \multicolumn{6}{|c|}{ Deviance Residuals } \\
\hline Coefficients & $\begin{array}{l}\text { Min } \\
-1.8957 \\
\text { Estimate }\end{array}$ & $\begin{array}{l}\text { 1Q } \\
-1.1908 \\
\text { Std. Error }\end{array}$ & $\begin{array}{l}\text { Median } \\
-0.5229 \\
z\end{array}$ & $\begin{array}{l}3 \mathrm{Q} \\
0.4053 \\
\text { value }\end{array}$ & $\begin{array}{l}\operatorname{Max} \\
2.0381 \\
\operatorname{Pr}(>|z|)\end{array}$ \\
\hline (Intercept) & 2.151588 & 1.189088 & 1.809 & 0.07038 & \\
\hline Richness (S) & 0.047262 & 0.029796 & 1.586 & 0.1127 & \\
\hline Evenness (J) & 0.257953 & 1.530567 & 0.169 & 0.86616 & \\
\hline Total cover & 0.008509 & 0.009729 & 0.875 & 0.38176 & \\
\hline Shrub cover & -0.00786 & 0.016917 & -0.465 & 0.64204 & \\
\hline Herb cover & -0.03672 & 0.012177 & -3.016 & 0.00257 & $* *$ \\
\hline Shrub height & 0.121006 & 0.15448 & 0.783 & 0.43344 & \\
\hline Herb height & -0.02453 & 0.010567 & -2.321 & 0.02026 & $*$ \\
\hline
\end{tabular}

Marked values are significant at $\alpha \leq 0.05$

Signif. codes: ' $* * *$ ' 0.001 '**' 0.01 '*' 0.05

(Dispersion parameter for Negative Binomial (1.0877) family taken to be 1)

Null deviance 127.259 on 89 degrees of freedom

Residual deviance 98.105 on 82 degrees of freedom

AIC 366.2

Number of Fisher Scoring iterations 1

Theta 1.088

Std. Err. 0.263

$2 \times$ log-likelihood -348.202

\section{Discussion}

Our study revealed that the distribution pattern and establishment of target dry grassland orchid species are affected by the surrounding vegetation, both on the horizontal and vertical plane, while other attributes such as species richness and evenness were not significant. These findings support the theory of microsite limitation, which assumes that one of the most important constraints to plant establishment is the availability of micro-habitats on the soil surface suitable for seed germination and seedling establishment (Jacquemyn et al. 2007). Indeed, the abundance of orchids was higher where the surrounding vegetation was discontinuous, leaving gaps of bare ground. In particular, increased cover and height of the herbaceous layer significantly decreased the cover of orchid populations.

Our results are consistent with previous studies suggesting that the extent of flowering of orchid populations is affected by competition with the surrounding vegetation (Dorland and Willems 2002;
Willems et al. 1993). Landi et al. (2009) found that a high abundance of orchids on calcareous grassland was positively correlated to the presence of microenvironments with rockiness and low herbaceous cover. A tall and dense herb layer outcompete orchid species by reducing the amount of available light (Janećková et al. 2006; Maccherini 2006). In particular, terrestrial orchid species require high light intensities close to the ground to obtain sufficient energy for successful fruiting and the completion of the life cycle (Dorland and Willems 2002, 2006; Jacquemyn et al. 2010).

Rather surprisingly, we found that neither cover nor height of the shrub species significantly affected orchid populations. Arguably, this result is likely due to the fact that although variable, shrub cover was typically low in the majority of plots when compared to herbaceous cover. Thus, shrub species did not affect orchid abundance for the simple reason that they were sporadic. Moreover, some studies have suggested that in a grassland/scrubland mosaic, shrub species might actually favour the persistence of grassland species, offering shelter from extreme drought and heat, 
Fig. 1 Orchid cover as a function of herbaceous vegetation height and cover

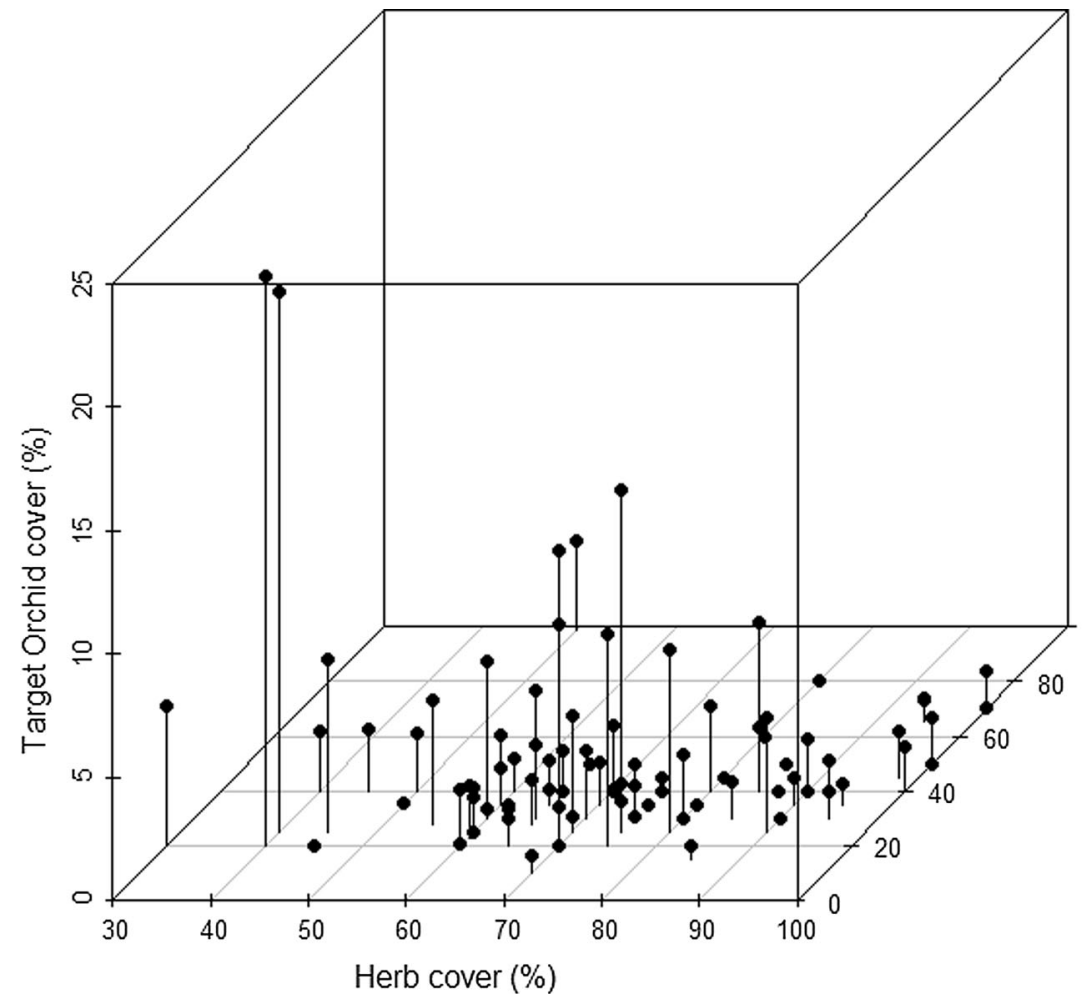

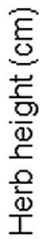

Table 2 Results of regression models between the fruit/flower ratio (FFr) and the inflorescence height relative to mean herbaceous vegetation height $(\mathrm{rRH})$

\begin{tabular}{llllllllr}
\hline Species & & $\beta$ & $S E$ & $t \beta$ & $p \beta$ & Adj $R^{2}$ & $F$ & $p F$ \\
\hline A. morio & Intercept & & & 5.464 & $<0.0001$ & 0 & 0.0003 & 0.987 \\
& rRH & 0.002 & 0.132 & 0.016 & 0.988 & & 59 \\
H. adriaticum & Intercept & & & 18.795 & $<0.0001$ & 0.775 & 172.35 & $<0.0001$ \\
& rRH & 0.880 & 0.067 & 13.128 & $<0.0001$ & & 52 \\
O. sphegodes & Intercept & & & 9.066 & $<0.0001$ & 0.179 & 20.95 & $<0.0001$ \\
& rRH & 0.435 & 0.095 & 4.577 & $<0.0001$ & & 92
\end{tabular}

$\beta$ regression coefficients estimates, $S E$ standard errors of $\beta, t \beta$ and $p \beta$ t Student statistics and $p$ values for the significance of $\beta, A d j$ $R^{2}=R^{2}$ corrected for the regression model, $F$ and $p F$ Fisher statistics and associated $p$ value for the significance of the model, $n$ number of cases (marked ramets)

predation and excessively early spring mowing (Armas et al. 2011; Bertness and Callaway 1994; ZifferBerger et al. 2014). However, in more extreme circumstances, where semi-natural grasslands are abandoned and dominance shifts from herbs to woody species, transition to scrublands or woodlands creates habitats where grassland orchids would be overcome by most species and lose their regeneration niche (Poorter 2007; Santiago et al. 2013; Zhang et al. 2014). The natural succession of vegetation and the entry of woody species can thus exclude orchids, and disturbances such as mowing or grazing interrupt succession allowing orchids to persist.

Among the monitored species, only $H$. adriaticum has been found on open dry grasslands as well as under shrub canopies. The species has a wider ecological plasticity compared to $O$. sphegodes and A. morio, and it is known to be able to live in scrubland/dry grassland mosaics (Bodis and Molnar 2009), although it is still unclear whether this is due to precise ecological 


\section{A. morio}

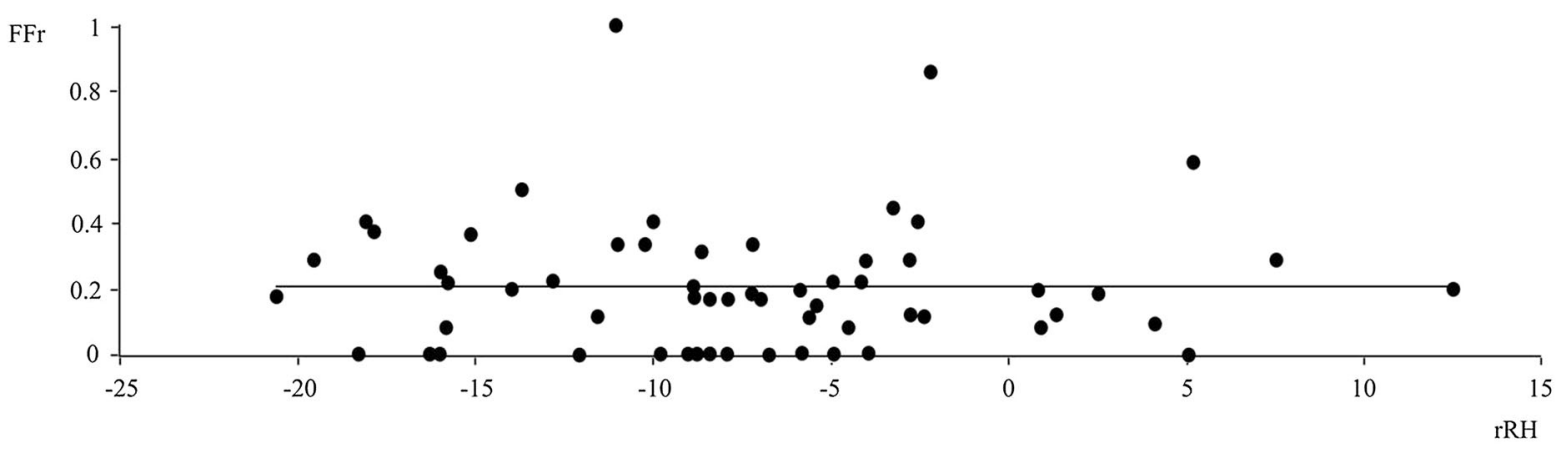

\section{H. adriaticum}

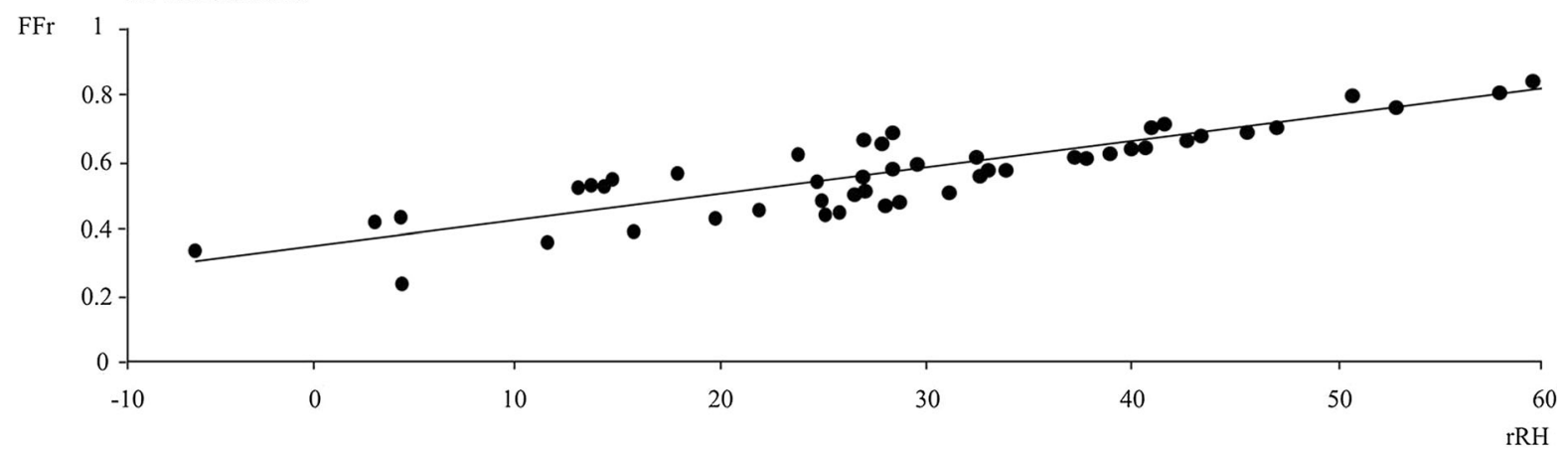

O. sphegodes

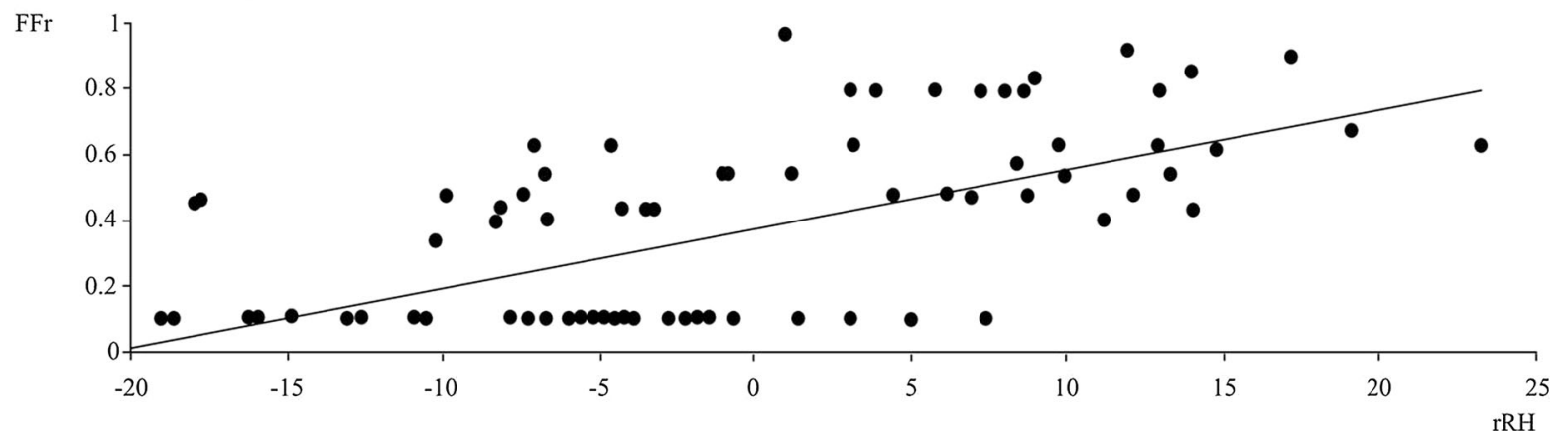

Fig. 2 Scatterplots of fruit/flower ratio (FFr) versus inflorescence height relative to mean herbaceous vegetation height (rRH, expressed in $\mathrm{cm}$ ) for A. morio, H. adriaticum and $O$. sphegodes. See Table 2 for details

requirements (Bodis and Botta-Dukat 2008; Pecoraro et al. 2013), or populations found under a shrub canopy represent residual populations of former open dry grasslands invaded by shrubs after the abandonment of traditional management practices (Bodis and Molnar 2009). Indeed, despite the fact that $H$. adriaticum may be present under a tree canopy, this species was consistently found very close to open areas and it was never found in a continuous woodland understorey.
At the ramet level, our study proved a strong effect of the height of the herb layer on the fruit set of $O$. sphegodes and $H$. adriaticum in accordance with their respective ramet heights: in those individuals that were able to raise their inflorescence over the surrounding vegetation, the fruit set was richer. This suggests a greater visitation rate by pollinators to the tallest inflorescences, perhaps due to a greater visual attraction. 
It is known that the structure of vegetation surrounding orchid populations could select for those ramets that are able to attract pollinators on their inflorescence and in this sense, limit pollinator availability only to ramets bearing visible floral displays (Kindlmann and Jersáková 2006). Pollinator attraction and thus reproductive success in plants generally increase with greater floral display size (Grindeland et al. 2005), but for strongly pollinator-limited deceptive orchids, there is some evidence that inflorescence height is a target of pollinator-mediated phenotypic selection (e.g. Sletvold and Ågren 2011; Walsh et al. 2014).

Therefore, it could be hypothesised that pollinatormediated selection of flowering stalk height operates for $O$. sphegodes and $H$. adriaticum. However, such selection would be relative to the surrounding herbaceous vegetation height and not absolute (i.e. it may not act on absolute flowering stalk height per se). Our findings are consistent with those of Sletvold et al. (2013) and Sletvold and Ågren (2014) who demonstrated that pollinator-mediated selection for taller plants is stronger in tall vegetation for the deceptive orchid Dactylorhiza lapponica but is not active in short vegetation and is weaker for the rewarding orchid Gymnadenia conopsea.

Pollinator-mediated selection on inflorescence height was supposed by Peakal and Handel (1993) for the Australian orchid Chiloglottis trilabra, whose pollinators discriminated among floral heights in a choice experiment. An increase in pollination due to greater plant height was found also for American food deceptive Cypripedium species (O'Connel and Johnson 1998; Wake 2007).

In contrast, according to our results, this selection is lacking for A. morio, since fruit set was not affected by relative ramet height. There are two main possible explanations: a greater intrinsic visibility of its inflorescence and reduced vegetation height. The deep purple inflorescence of A. morio could have much more attractive power towards pollinators with respect to the brownish or white flowers of the other two target species that blend into the greenish herb layer, since stronger colours are supposedly more tempting to pollinating bees than weak colours (Willimer 2011). As for the second reason, mean herbaceous vegetation height in A. morio plots was just $25 \mathrm{~cm}$ and such a low value may depress the expression of pollinator-mediated selection (Sletvold and Ågren 2014) being almost equal to the mean flowering stalk height $(24.5 \pm 5.4 \mathrm{~cm})$. Indeed, Pierce et al. (2014) determined, although for only one particular xeric grassland site, that shorter orchids including A. morio flowered earlier in the season when the dominant grass species were still relatively short, and that only taller orchid species such as Anacamptis pyramidalis flowered later when the grass height was at its peak.

Despite high species richness being perhaps the most evident feature of dry grasslands, the distribution of target orchid species was not sensitive to species richness or evenness. Such a finding negates the possibility of a suite of species-specific relationships with non-orchid species or, in the case that any of these relationships were important, that they would arise between orchids and restricted groups of species but not at the community level.

In conclusion, this study demonstrates that target dry grassland orchid species are very sensitive to herbaceous vegetation structure rather than to the structure of the woody component of the plant community. This implies a major role of interactions between orchids and more competitive herbaceous species (graminoids in particular). In contrast, encroachment of woody species following abandonment is a relatively drastic effect that represents the start of ecological succession, rather than the finescale relationships that occur within plant communities and that determine which species can persist locally in dry grasslands of subtly different structure. Indeed, 'dry calcareous grassland' is a broad category that can include a range of different non-orchidaceous species, vegetation heights and thus different orchid species. It is well known that structure, functioning and dynamics in semi-natural habitats are primarily governed through the maintenance of traditional human practices. Mowing, grazing as well as reduced fertilizer application are common features of most well-preserved species-rich grasslands in Europe. Long-term low-intensity management is then an important component in community assembly regulating species composition and richness, species abundance and flowering phenology. As confirmed by our investigation, structural attributes of surrounding vegetation can also influence small-scale interactions between orchid species and the extant community such as the rate of pollinator visitation, thus affecting the overall expression of coexistence mechanisms between grassland species. However, this 
study demonstrated experimentally that there can be substantial variation in the response of different species and variation in the structural attributes of surrounding vegetation may be associated with differences in the strength of selection. Thus, what the present study adds is that a subtle effect exists whereby local herbaceous vegetation structure is related to the cover and fruit set for each particular orchid species. Protocols for the in situ conservation of each species must therefore detail the range of vegetation covers and heights (and ideally, precise management actions) at which different species are favoured and can produce the most effective inflorescences.

\section{References}

Ackerman JD, Sabat A, Zimmerman JK (1996) Seedling establishment in an epiphytic orchid: an experimental study of seed limitation. Oecologia 106:192-198

Anonymous (1992) European Communities Council, Directive 92/43/CEE on the Conservation of Natural Habitats and of Wild Fauna and Flora. European Communities, Brussels

Armas C, Rodriguez-Echeverria S, Pugnaire FI (2011) A field test of the stress-gradient hypothesis along an aridity gradient. J Veg Sci 22:818-827

Baskin CC, Baskin JM (2014) Seeds: ecology biogeography and evolution of dormancy and germination. Academic Press, San Diego

Bertness MD, Callaway R (1994) Positive interactions in communities. Trends Ecol Evol 9:191-193

Bini C (2001) I suoli dei Colli Euganei. Padova, Italy

Biondi E, Casavecchia S, Pesaresi S (2006) Spontaneous renaturalization processes of the vegetation in the abandoned fields (Central Italy). Ann Bot 6:65-93

Bobbink R, Willems JH (1987) Increasing dominance of Brachypodium pinnatum (L.) Beauv. in chalk grasslands: a threat to a species-rich ecosystem. Biol Conserv 40:301-314

Bódis J, Botta-Dukát Z (2008) Growth of Himantoglossum adriaticum and $H$. caprinum individuals, and relationship between sizes and flowering. Acta Bot Hung 50:257-274

Bódis J, Molnár E (2009) Long-term monitoring of Himantoglossum adriaticum $\mathrm{H}$. Baumann population in Keszthely hills, Hungary. Natura Somogyiensis 15:27-40

Brooker RW, Maestre FT, Callaway RM et al (2008) Facilitation in plant communities: the past, the present, and the future. J Ecol 96:18-34

Burgeff H (1959) Mycorrhiza of orchids. In: Withner C (ed) The orchids: a scientific survey. Ronald Press, New York, pp 361-395

Clark JS, Silman M, Kern R, Macklin E, HilleRisLambers J (1999) Seed dispersal near and far: patterns across temperate and tropical forests. Ecology 80:1475-1494

Coates F, Lunt ID, Tremblay RL (2006) Effects of disturbance on population dynamics of the threatened orchid Prasophyllum correctum DL Jones and implications for grassland management in south-eastern Australia. Biol Conserv 129:59-69

Cornelissen JHC, Lavorel S, Garnier E et al (2003) A handbook of protocols for standardised and easy measurement of plant functional traits worldwide. Austral $\mathrm{J}$ Bot 51:335-380

Cozzolino S, Widmer A (2005) Orchid diversity: an evolutionary consequence of deception? Trends Ecoland Evol 20(9):487-494

Delforge P (2001) Guide des orchidées d'Europe. Delachaux et Niestlé, Lausanne

Dengler J, Janišová M, Török P, Wellstein C (2014) Biodiversity of Palaearctic grasslands: a synthesis. Agric Ecosyst Environ 182:1-14

Djordjević V, Tsiftsis S, Lakušić D, Jovanović S, Stevanović V (2016) Factors affecting the distribution and abundance of orchids in grasslands and herbaceous wetlands. Syst Biodivers 14(4):355-370

Dorland E, Willems JH (2002) Light climate and plant performance of Ophrys insectifera: a 4-year field experiment in The Netherlands 1998-2001. In: Kindlmann P, Willems JH, Whigham DF (eds) Trends and fluctuations and underlying mechanisms in terrestrial orchid populations. Backhuys Publishers, Leiden, pp 225-238

Dorland E, Willems JH (2006) High light availability alleviates the costs of reproduction in Ophrys insectifera (Orchidaceae). J Europäischer Orchideen 38:501-518

Eriksson O (1995) Seedling recruitment in deciduous forest herbs - the effects of litter, soil chemistry and seed bank. Flora 190:65-70

Fantinato E, Del Vecchio S, Slaviero A, Conti L, Acosta ATR, Buffa G (2016) Does flowering synchrony contribute to the sustainment of dry grassland biodiversity? Flora 15:304-318

Fischer M, Stocklin J (1997) Local extinctions of plants in remnants of extensively used calcareous grasslands 1950-1985. Conserv Biol 11:727-737

García-Camacho R, Iriondo JM, Escudero A (2010) Seedling dynamics at elevation limits: complex interactions beyond seed and microsite limitations. Am J Bot 97:1791-1797

Gregg KB (2004) Recovery of showy lady's slippers (Cypripedium reginae Walter) from moderate and severe herbivory by white-tailed deer (Odocoileus virginianus Zimmerman). Nat Area J 24:232-241

Grindeland JM, Sletvold N, Ims RA (2005) Effects of floral display size and plant density on pollinator visitation rate in a natural population of Digitalis purpurea. Funct Ecol 19:383-390

Gurevitch J, Scheiner SM, Fox GA (2002) The ecology of plants. Sinauer Associates Inc, Sunderland

Habel JC, Dengler J, Janišová M, Török P, Wellstein C, Wiezik M (2013) European grassland ecosystems: threatened hotspots of biodiversity. Biodiv Conserv 22:2131-2138

Hutchings MJ, Mendoza A, Havers W (1998) Demographic properties of an outlier population of Orchis militaris L. (Orchidaceae) in England. Bot J Linnean Soc 126:95-107

IUCN (1999) IUCN guidelines for the prevention of biodiversity loss due to biological invasion. Species 31(32):28-42

Jacquemyn H, Brys R (2015) Pollen limitation and the contribution of autonomous selfing to fruit and seed set in a rewarding orchid. Am J Bot 102:67-72 
Jacquemyn H, Brys R, Vandepitte K, Honnay O, Roldan-Ruiz I, Wiegand T (2007) A spatially explicit analysis of seedling recruitment in the terrestrial orchid Orchis purpurea. New Phytol 176:448-459

Jacquemyn H, Brys R, Jongejans E (2010) Size-dependent flowering and costs of reproduction affect population dynamics in a tuberous perennial woodland orchid. J Ecol 98:1204-1215

Janećková $\mathrm{P}$, Wotavová $\mathrm{K}$, Schödelbauerová I, Jersáková J, Kindlmann P (2006) relative effects of management and environmental conditions on performance and survival of populations of a terrestrial orchid, Dactylorhiza majalis. Biol Conserv 129:40-49

Janišová M, Bartha S, Kiehl K, Dengler J (2011) Advances in the conservation of dry grasslands: introduction to contributions from the seventh European dry grassland meeting. Plant Biosyst 145:507-513

Kindlmann P, Jersáková J (2006) Effect of floral display on reproductive success in terrestrial orchids. Folia Geobot 41:47-60

Kull T, Hutchings MJ (2006) A comparative analysis of decline in the distribution ranges of orchid species in Estonia and the United Kingdom. Biol Conserv 129:31-39

Landi M, Frignani F, Lazzeri C, Angiolini C (2009) Abundance of orchids on calcareous grasslands in relation to community species, environmental, and vegetational conditions. Russ J Ecol 40:486-494

Maccherini S (2006) Factors associated with species richness in a remnant calcareous grassland. Grassland Sci 52:181-184

Magurran AE (2004) Measuring biological diversity. Blackwell Publishing, Malden

Mason NWH, de Bello F, Dolezal J, Leps J (2011) Niche overlap reveals the effects of competition, disturbance and contrasting assembly processes in experimental grassland communities. J Ecol 99:788-796

Moeller DA (2004) Facilitative interactions among plants via shared pollinators. Ecology 85:3289-3301

Moles AT, Westoby M (2004) What do seedlings die from and what are the implications for evolution of seed size? Oikos 106:193-199

O'Connell LM, Johnston MO (1998) Male and female pollination success in a deceptive orchid, a selection study. Ecology 79:1246-1260

Peakall R, Handel SN (1993) Pollinators discriminate among floral heights of a sexually deceptive orchid-implications for selection. Evolution 47:1681-1687

Pecoraro L, Girlanda M, Kull T, Perini C, Perotto S (2013) Fungi from the roots of the terrestrial photosynthetic orchid Himantoglossum adriaticum. Plant Ecol Evol 146:145-152

Pierce S, Belotti J (2011) The conservation of terrestrial orchids from the Alps to the Po plain of Lombardy, Albino (BG) and Galbiate (LC), Italy. Parco Orobie Bergamasche, CFA Regione Lombardia

Pierce S, Ceriani R, Villa M, Cerabolini B (2006) Quantifying relative extinction risks and targeting intervention for the orchid flora of a natural park in the European prealps. Conserv Biol 20(6):1804-1810

Pierce S, Vagge I, Brusa G, Cerabolini BEL (2014) The intimacy between sexual traits and Grime's CSR strategies for orchids coexisting in semi-natural calcareous grassland at the Olive Lawn. Plant Ecol 215:495-505
Poorter L (2007) Are species adapted to their regeneration niche, adult niche, or both? Am Nat 169:433-442

Rezende VL, Eisenlohr PV, Vibrans AC, de Oliveira AT (2015) Humidity, low temperature extremes, and space influence floristic variation across an insightful gradient in the subtropical Atlantic forest. Plant Ecol 216:759-774

Ricotta C (2007) A semantic taxonomy for diversity measures. Acta Biotheor 55:23-33

Roy BA, Widmer A (1999) Floral mimicry: a fascinating yet poorly understood phenomenon. Trends Plant Sci $4: 325-330$

Santiago A, Herranz JM, Copete E, Ferrandis P (2013) Speciesspecific environmental requirements to break seed dormancy: implications for selection of regeneration niches in three Lonicera (Caprifoliaceae) species. Botany-Botanique 91:225-233

Sharrock S, Jones M (2009) Conserving Europe's threatened plants. Progress towards target 8 of the global strategy for plant conservation. Botanic Gardens Conservation International, Richmond

Silvertown J, Wells DA, Gillman M, Dodd ME, Robertson H, Lakhani KH (1994) Short-term effects and long-term aftereffects of fertilizer application on the flowering population of Green-winged Orchid Orchis morio. Biol Conserv 69:191-197

Sletvold N, Ågren J (2011) Nonadditive effects of floral display and spur length on reproductive success in a deceptive orchid. Ecology 92:2167-2174

Sletvold N, Ågren J (2014) There is more to pollinator-mediated selection than pollen limitation. Evolution 68:1907-1918

Sletvold N, Grindeland JM, Ågren J (2013) Vegetation context influences the strength and targets of pollinator-mediated selection in a deceptive orchid. Ecology 94:1236-1242

Sonkoly J, Vojtkó EA, Tökölyi J, Török P, Sramkó G, Illyés Z, Molnár VA (2016) Higher seed number compensates for lower fruit-set in deceptive orchids. J Ecol 104:343-351

Strauss SY, Irwin RE (2004) Ecological and evolutionary consequences of multispecies plant-animal interactions. Ann Rev Ecol Evol Syst 35:435-466

Svenning JC, Fabbro T, Wright SJ (2008) Seedling interactions in a tropical forest in Panama. Oecologia 155:143-150

Swarts ND, Dixon KW (2009) Terrestrial orchid conservation in the age of extinction. Ann Bot 104:543-556

Thuiller W, Lavorel S, Araujo MB (2005) Niche properties and geographical extent as predictors of species sensitivity to climate change. Global Ecol Biogeogr 14:347-357

Tsiftsis S, Tsiripidis I, Karagiannakidou V, Alifragis D (2008) Niche analysis and conservation of the orchids of east Macedonia (NE Greece). Acta Oecol 33:27-35

Tsvuura Z, Griffiths ME, Gunton RM, Franks PJ, Lawes MJ (2010) Ecological filtering by a dominant herb selects for shade tolerance in the tree seedling community of coastal dune forest. Oecologia 164:861-870

Valkó O, Török P, Matus G, Tóthmérész B (2012) Is regular mowing the most appropriate and cost-effective management maintaining diversity and biomass of target forbs in mountain hay meadows? Flora 207:303-309

Venables WN, Ripley BD (2002) Modern applied statistics with $\mathrm{S}, 4$ th edn. Springer, New York

Vogt-Schilb H, Munoz F, Richard F, Schatz B (2015) Recent declines and range changes of orchids in Western Europe 
(France, Belgium and Luxembourg). Biol Conserv 190:133-141

Wake CM (2007) Micro-environment conditions, mycorrhizal symbiosis, and seed germination in Cypripedium candidum: strategies for conservation. Lankesteriana 7:423-426

Walsh RP, Arnold PM, Michaels HJ (2014) Effects of pollination limitation and seed predation on female reproductive success of a deceptive orchid. AoB Plants 6:1-12

Willems JH, Peet RK, Bik L (1993) Changes in chalk-grassland structure and species richness resulting from selective nutrient additions. J Veg Sci 4:203-212

Willimer P (2011) Pollinator and floral ecology. Princeton University Press, Princeton
Wotavova K, Balounova Z, Kindlmann P (2004) Factors affecting persistence of terrestrial orchids in wet meadows and implications for their conservation in a changing agricultural landscape. Biol Conserv 118:271-279

Zhang CH, Willis CG, Burghardt LT, Qi W, Liu K, Souza PRM, Ma Z, Du GZ (2014) The community-level effect of light on germination timing in relation to seed mass: a source of regeneration niche differentiation. New Phytol 204:496-506

Ziffer-Berger J, Weisberg PJ, Cablk ME, Osem Y (2014) Spatial patterns provide support for the stress-gradient hypothesis over a range-wide aridity gradient. J Arid Envir 102:27-33 